\title{
Review Article \\ Review of the Strain Modulation Methods Used in Fiber Bragg Grating Sensors
}

\author{
Kuo Li \\ School of Civil Engineering and Built Environment, Queensland University of Technology, Brisbane, QLD 4000, Australia \\ Correspondence should be addressed to Kuo Li; tolikuo@gmail.com
}

Received 4 October 2015; Revised 23 December 2015; Accepted 29 December 2015

Academic Editor: Emily J. Hao

Copyright (C) 2016 Kuo Li. This is an open access article distributed under the Creative Commons Attribution License, which permits unrestricted use, distribution, and reproduction in any medium, provided the original work is properly cited.

\begin{abstract}
Fiber Bragg grating (FBG) is inherently sensitive to temperature and strain. By modulating FBG's strain, various FBG sensors have been developed, such as sensors with enhanced or reduced temperature sensitivity, strain/displacement sensors, inclinometers, accelerometers, pressure meters, and magnetic field meters. This paper reviews the strain modulation methods used in these FBG sensors and categorizes them according to whether the strain of an FBG is changed evenly. Then, those even-strain-change methods are subcategorized into (1) attaching/embedding an FBG throughout to a base and (2) fixing the two ends of an FBG and (2.1) changing the distance between the two ends or (2.2) bending the FBG by applying a transverse force at the middle of the FBG. This review shows that the methods of "fixing the two ends" are prominent because of the advantages of large tunability and frequency modulation.
\end{abstract}

\section{Introduction}

FBG sensors have many inherent advantages over conventional electrical sensors, such as frequency modulation, immunity to electromagnetic interference, and nonconductivity [1-4]. These advantages are ideal for many applications such as structural health monitoring [5-8], medical applications [9-13], and seismic monitoring [14-17], especially for the applications where strong electromagnetic interference exists or nonconductivity is essential, such as nuclear reactors [18-20] and hydrogen tanks [21, 22]. FBG sensors have been successfully commercialized in many structural health monitoring applications, being an emerging substitute for electrical ones [23-27].

This review focuses on how the strain of an FBG is modulated in various FBG sensors, whereas comprehensive reviews on optical fiber sensors $[28,29]$ and fiber Bragg gratings [30] are available.

\section{Working Principle of FBG}

The working principle of FBG is shown in Figure 1. Bragg gratings are formed on the core of a single mode fiber by changing its refractive index. When a broadband light goes through an FBG, the light at a certain wavelength will be reflected while all the other light will go through.

The resonant wavelength (the central wavelength of the reflected light) is [4]

$$
\lambda=2 n_{\mathrm{eff}} \Lambda,
$$

where $n_{\text {eff }}$ is the effective reflective index of the fiber core and $\Lambda$ is the grating period.

When the strain $\varepsilon$ changes [30],

$$
\Delta \lambda=\lambda(1-\rho) \Delta \varepsilon,
$$

where $\rho$ is the stress-optic coefficient. When temperature changes, the resonant wavelength will also change. Its inherent temperature sensitivity is about $10 \mathrm{pm} /{ }^{\circ} \mathrm{C}$.

The strain of an FBG has been modulated for varying its temperature sensitivity [31-40] and monitoring strain/displacement [41-49], inclination [50-56], acceleration [57-68], pressure [69-78], magnetic field [79-88], and rotation [89]. 


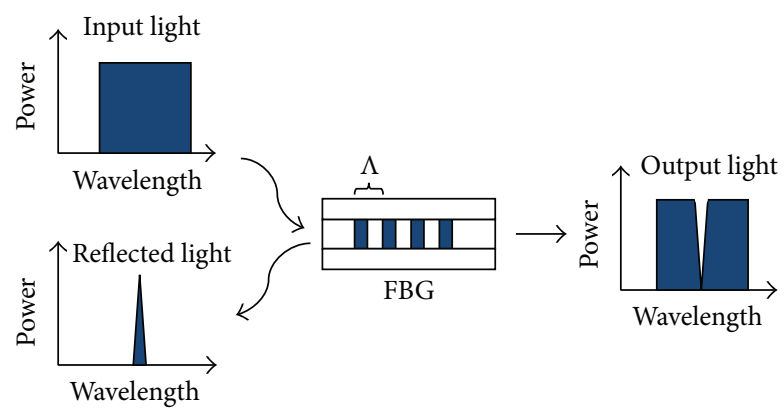

FIgURE 1: Working principle of an FBG.

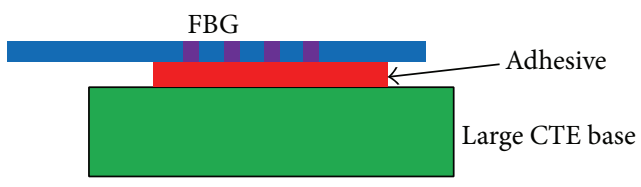

FIGURE 2: Large CTE base bonding method for temperature measurement [31].

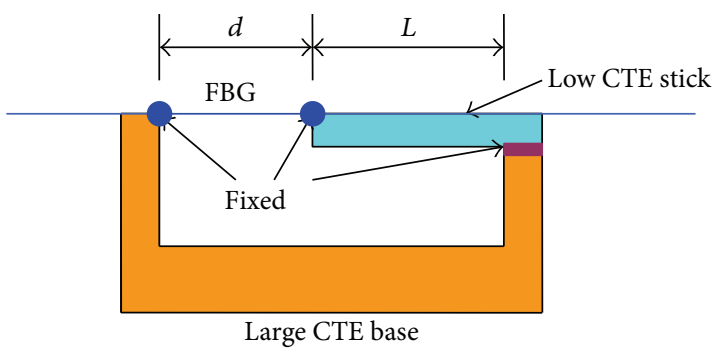

FIGURE 3: Bimetal method [33].

\section{FBG Sensors}

\subsection{Varying Temperature Sensitivity}

3.1.1. Large Coefficient of Thermal Expansion (CTE) Base Bonding Method. In order to increase its temperature sensitivity, an FBG was initially bonded to a base with a large Coefficient of Thermal Expansion (CTE), as shown in Figure 2 $[31,32]$. When temperature changes, the strain of the FBG will change as much as that of the large CTE base. So the FBG becomes more sensitive to temperature.

3.1.2. Initial Bimetal Method. However, the sensitivity achieved in the above method is limited by the CTE of the base. Bimetal method was introduced to overcome this limitation, as shown in Figure 3 [33]. Assume that the length of the low CTE stick is $L$, and the distance between the fixed ends of the FBG is $d$. When temperature changes, the length-change of the large CTE base will be transferred to the FBG. To roughly estimate the strain change of the FBG, the temperature-induced, tiny length-change of the low CTE stick can be ignored. So the strain change of the FBG is $(1+L / d)$ times that of the base. The strain change of the FBG is no longer solely decided by the CTE of the base, and ambient temperature sensitivity can be achieved.

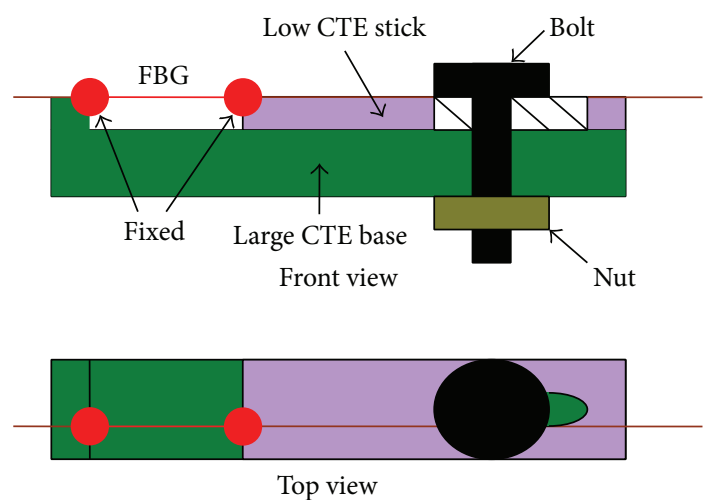

Figure 4: Bimetal method with adjustable measurement range [38].

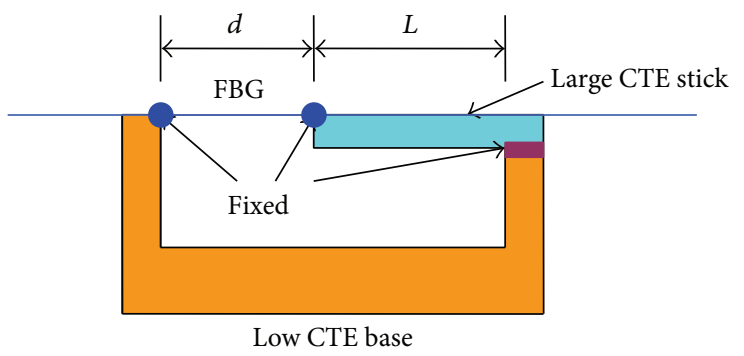

FIgURE 5: Bimetal method for low temperature monitoring [37].

3.1.3. Bimetal Method with Adjustable Measurement Range. To make full use of the limited range of the strain change of an FBG to achieve the highest sensitivity possible for high temperature monitoring, the FBG in Figure 3 should be relaxed at room temperature. As temperature increases, it starts to be stretched at the low-limit of its measurement range and fully stretched at the up-limit [38]. Figure 4 shows the mechanics for achieving this function. The low CTE stick has a slot thereon. By adjusting the position of this stick, the FBG can be prerelaxed for a certain length so that it starts to be stretched at the low-limit. With proper design of its sensitivity, the strain of an FBG can be fully used.

3.1.4. Bimetal Method for Low Temperature Monitoring. However, only the large CTE base bonding method had been used for monitoring cryogenic temperature [34-36], because the initial bimetal method relaxes the FBG as temperature goes down rather than stretching it. A bimetal FBG sensor with negative temperature coefficient was demonstrated to achieve ambient sensitivity at low temperature by exchanging the positions of the bimetals, as shown in Figure 5 [37]. When temperature goes down, the FBG will be stretched, and ambient sensitivity can be achieved.

3.1.5. Bimetal Method for Temperature Compensation. In order to eliminate the influence of temperature, the strain of an FBG can be changed to compensate its inherent temperature sensitivity. By using the abovementioned bimetal methods to make the temperature sensitivity zero [37], 


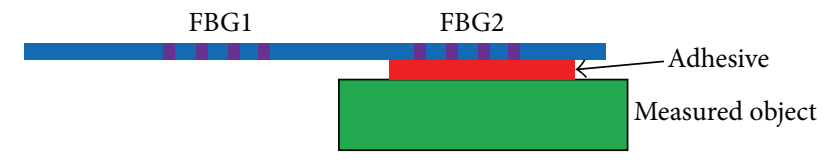

FIGURE 6: Simultaneous temperature and strain monitoring [44].

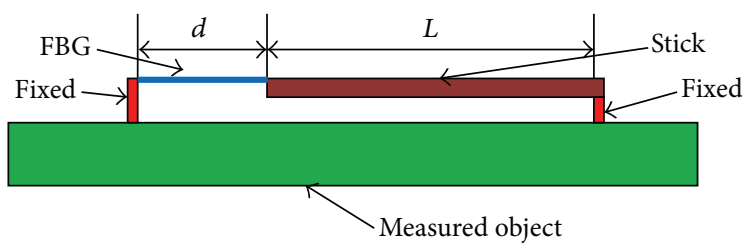

FIGURE 7: Strain monitoring by one FBG with automatic temperature compensation [48].

temperature-independent devices can be achieved [39, 40, 51].

3.2. Strain/Displacement Measurement. In strain/displacement measurement, as both strain and temperature are quasistatic in many applications, the strain has to be distinguished from the temperature.

\subsubsection{Simultaneous Monitoring of Strain and Temperature.} One extensively investigated method is to monitor both strain and temperature and then eliminate the influence of the temperature to determine the strain, which usually requires two FBGs [43-45]. Figure 6 shows one example. FBG2 is glued throughout on the measured object, whereas FBG1 is not. When the strain of the measured object changes, only FBG2 will respond; when temperature changes, both of them will respond. Based on the temperature response of FBG1, the temperature influence on FBG2 can be eliminated from its response, and the strain of the measured object can be obtained.

3.2.2. Strain Monitoring by One FBG with Automatic Temperature Compensation. Temperature can also be compensated by the temperature-induced length-change of a stick connected to the FBG, so that only one FBG is needed [48]. Figure 7 shows the principle. A tensioned FBG is fixed between a stick and the measured object. When only temperature changes, the temperature-induced length-change of the stick can keep the resonant wavelength unchanged. Therefore, the shift of the resonance wavelength of the FBG only represents the strain change of the measured object. When the measured strain changes, the stick does not change in length but the FBG does. So the strain change of the FBG is $(1+L / d)$ times that of the measured object. Unlike the bimetal temperature-compensation method, the temperature compensation here is only based on the stick.

3.2.3. Strain Monitoring by Unevenly Changing the Strain of an FBG. By unevenly changing the strain of an FBG, the strain of a measured object can also be distinguished by the

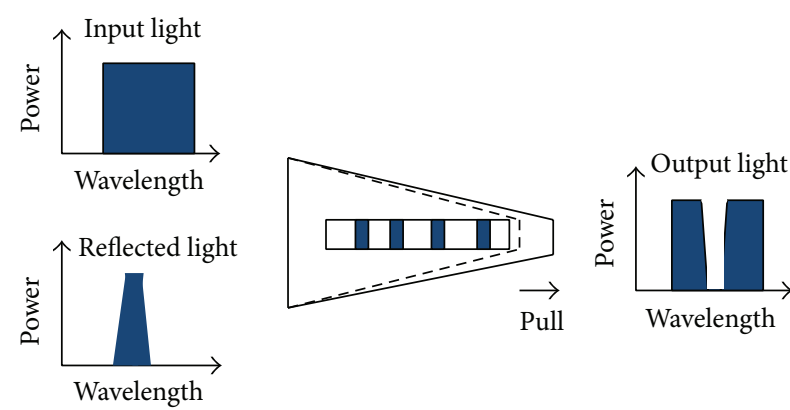

FIGURE 8: Strain monitoring by a chirped FBG [42].

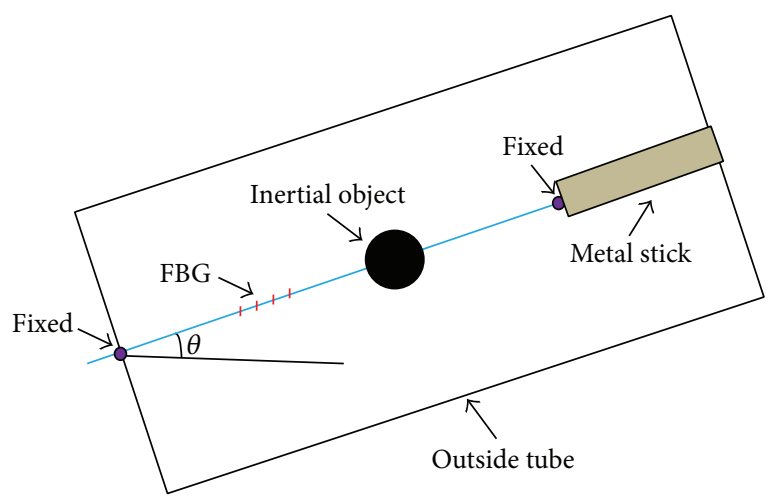

FIGURE 9: Uniaxial inclinometer [51].

power of the reflected light of an FBG, which is immune to temperature [42]. Figure 8 shows one example. The fiber is tapped, and its strain will change unevenly when it is pulled. The larger the uneven distribution, the wider the width of the reflected spectral response. When temperature changes, the width does not change, but its position shifts along the horizontal axis. However, this method loses the advantage of frequency modulation, as it is based on the power of the reflected spectrum rather than the resonant wavelength. FBG sensors based on this method are subject to noise produced by effects such as curves in the fiber.

3.3. FBG Inclinometers. FBG inclinometers have been developed by converting a tilted degree to the even or uneven strain change of an FBG. By connecting an inertial object with an FBG, the strain of FBG can be changed when the inclinometer is tilted.

3.3.1. Inclinometers Based on Even Strain Change. Figure 9 shows an FBG inclinometer by fixing an inertial object directly on an FBG [51]. If there is a tilted degree $\theta$ as shown, the inertial object will exert a force to extend the FBG. So the resonant wavelength of the FBG can represent the tilted degree. Temperature compensation can be achieved by the bimetal method $[39,40]$.

Figure 10 shows a planar biaxial inclinometer [52]. When there is an inclination, the resonant wavelength of the four FBGs will change. The difference between the resonant wavelengths of the two FBGs along one axis can be used to 


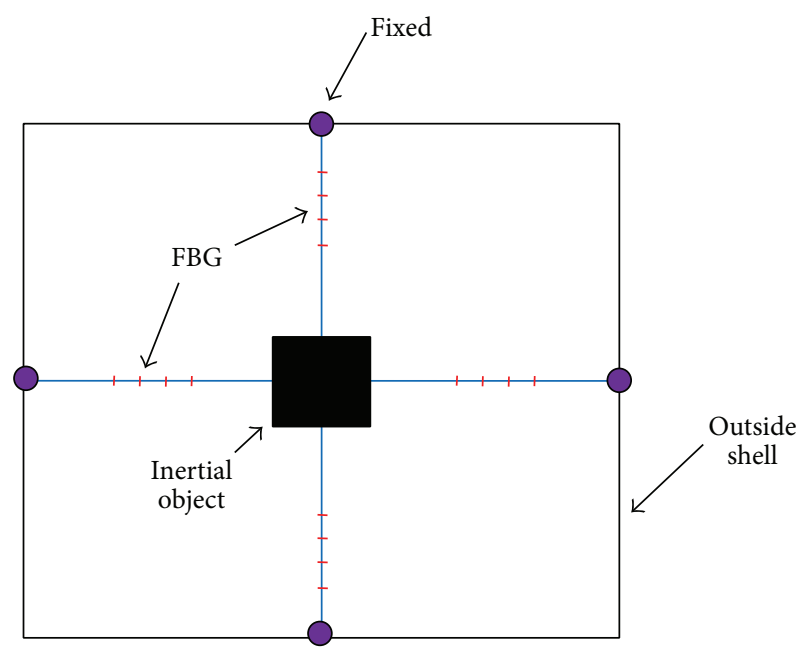

FIGURE 10: Top view of the planar biaxial inclinometer [52].

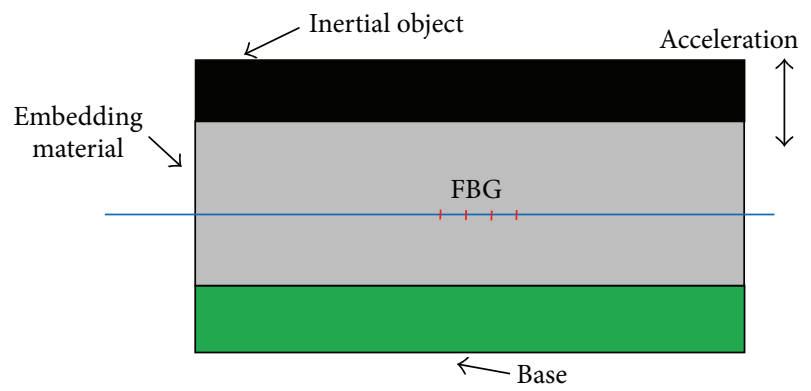

FIGURE 11: FBG accelerometer based on throughout attaching [65].

determine the inclination in that direction. The difference is immune to temperature, because temperature influences the two FBGs equally and the difference between them eliminates the influence.

3.3.2. Inclinometers Based on Uneven Strain Change. Since an inclinometer is based on the strain change of an FBG, the method of unevenly changing the strain of an FBG shown in Figure 8 can be adapted to monitor inclination, for example, the inclinometer in [50]. As discussed in Figure 8, this method relies on the reflected power rather than wavelength, losing the advantages of frequency modulation.

3.4. FBG Accelerometers. FBG accelerometers have been developed by using an inertial object to change the strain of an FBG according to the environmental acceleration.

3.4.1. FBG Accelerometers Based on Throughout Attaching. Figure 11 shows the first demonstration of FBG accelerometer [65]. In case of a vertical acceleration, the mass will move up and down. As a result, the strain of the FBG is changed periodically. Similar to the large CTE base bonding method used for high sensitivity temperature monitoring, this accelerometer cannot fully use the mass to exert large strain change of the FBG.

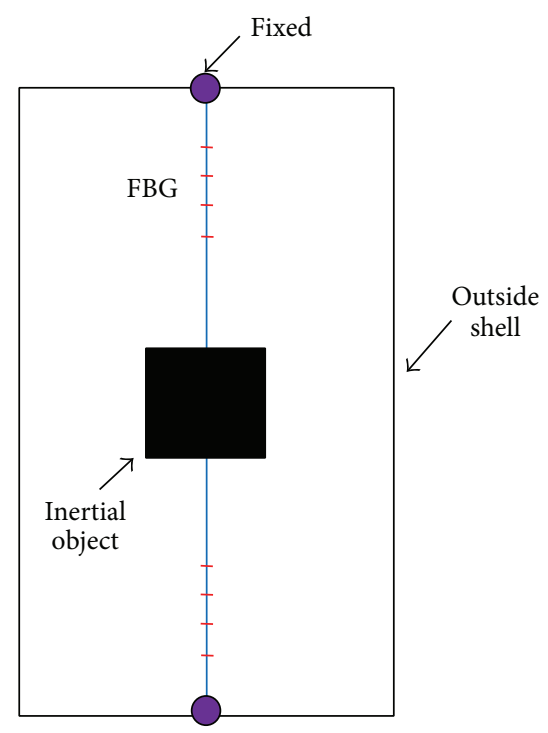

Figure 12: Uniaxial FBG accelerometer [66].

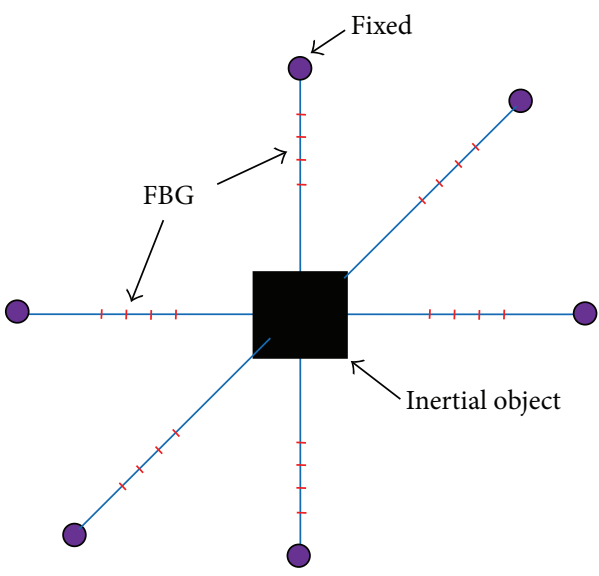

Figure 13: Triaxial FBG accelerometer [61].

3.4.2. FBG Accelerometers Based on Direct Forces. To achieve high sensitivity at low inertial mass, an FBG is fixed by its two ends, and an inertial mass is fixed at the middle of the FBG.

(1) FBG Accelerometers Using Axial Forces. Figure 12 shows a uniaxial FBG accelerometer using axial forces, which can transfer the movement of the inertial object into the displacement of the FBGs $[62,66]$. When the inertial object moves up and down, the lengths and resonant wavelengths of the two FBGs will be changed. The difference between the resonant wavelengths represents the acceleration and is immune to temperature.

Figure 13 shows a triaxial FBG accelerometer, which uses 6 FBGs for three orthogonal directions [61]. The difference between the resonant wavelengths of the two FBGs along one axis represents the acceleration in that direction and is immune to temperature. 
(2) FBG Accelerometers Using Transverse Forces. It has been demonstrated that when a transverse force applies to a lightly stretched string, it will induce a stronger axial force [67]. The optimum amplification condition is that the applying position is at the middle of the string, and the string is stretched as less as possible.

FBG accelerometers using transverse forces have two advantages: (1) requiring less FBGs for biaxial monitoring and (2) obtaining a higher sensitivity at the same inertial mass [58]. A biaxial FBG accelerometer was demonstrated by using a setup similar to that shown in Figure 12. The acceleration in the axial direction was distinguished by the difference of the resonant wavelengths of the two FBGs, while the acceleration in the transverse direction was distinguished by the average of the resonant wavelengths of the two FBGs. It was more sensitive to the transverse acceleration, as it was more sensitive to the transverse force.

3.5. FBG Pressure Sensors. When an FBG is exposed to a pressure, its strain will change. The relationship between the pressure applied and its induced strain change is [77]

$$
\Delta \varepsilon=-\frac{P(1-2 v)}{E},
$$

where $P, v$, and $E$ are the pressure applied, Poisson ratio, and Young's modulus of the fiber, respectively. However, the intrinsic pressure sensitivity is too low, only $3.14 \mathrm{pm} / \mathrm{MPa}$ [78]. The sensitivity was initially improved by embedding FBG into polymers (60 $\mathrm{pm} / \mathrm{MPa}[72])$.

The sensitivity is dramatically improved by fixing the two ends of an FBG and changing the axial distance between the ends (5.277 nm/MPa [74] and $33.876 \mathrm{~nm} / \mathrm{MPa}$ [71]). Temperature influence can be compensated by using the bimetal method [70] or by using the difference between the resonant wavelengths of two FBGs along one axis [69].

3.6. FBG Magnetic Field Sensors. By using a magnetostrictive material to change the strain of an FBG according to the magnetic field, many FBG magnetic field sensors have been developed [79-88]. This method was early reported in [87], and a resolution of $2 \mathrm{~mA}$ has been reported [88]. Temperature can be compensated by using a reference FBG $[80,81]$. To reduce the size, the cladding of the FBG was partially removed and then the magnetostrictive material was coated $[79,83,85]$.

\section{Categorization and Conclusion}

Numerous FBG sensors have been developed by various methods. Figure 14 categorizes these methods based on how the strain of an FBG is changed. According to whether an FBG is stretched evenly or unevenly, it is divided into two categories.

In the "unevenly" category, the strain of an FBG is changed unevenly. What changes along with the environmental input is no longer the resonant wavelength but the power of the reflected light. FBG sensors based on these methods, for example, the method of strain monitoring by a chirped FBG, lose the intrinsic advantages of frequency modulation

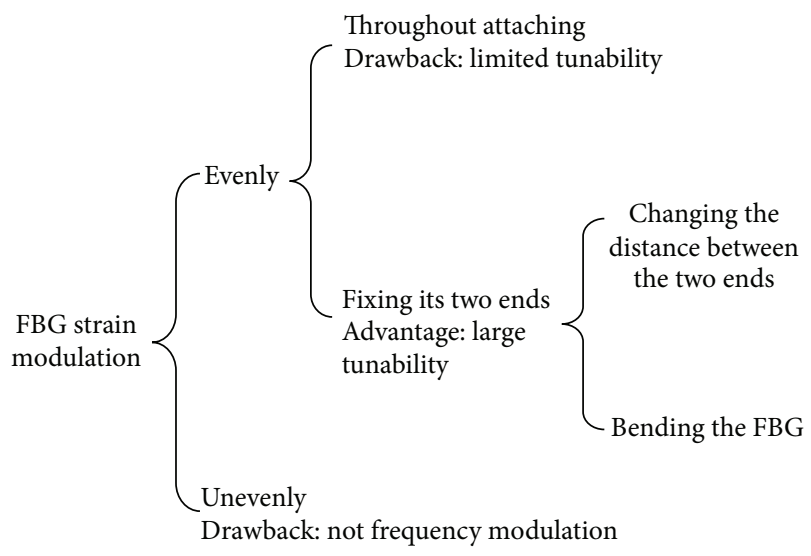

FIGURE 14: Categorization of FBG sensors according to how the strain of the FBG is changed.

and are subject to noise produced by effects such as curves in the fiber, although they are immune to temperature.

In the "evenly" category, there are two subcategories. The first subcategory, "throughout attaching," includes the large CTE base bonding method, the simultaneous-temperatureand-strain-monitoring method, the FBG accelerometers based on throughout attaching, polymer embedded pressure sensor, and the FBG magnetic field sensors. The drawback of these methods is that the strain of an FBG can only be changed very limitedly and therefore the sensitivity is usually low.

The second subcategory is "fixing the two ends of an FBG," which can be further subcategorized into (1) "changing the distance between the two ends" and (2) "bending the FBG." "Changing the distance between the two ends" includes the bimetal methods, the automatic temperaturecompensation method by using one FBG, the FBG inclinometers based on the even strain change, the FBG accelerometers based on direct axial forces, and the high sensitive FBG pressure sensors. These methods can change the strain of an FBG arbitrarily and effectively. "Bending the FBG" includes the FBG accelerometers using transverse forces [57$59,67]$, which can be used to increase the sensitivity and reduce the number of FBGs required for biaxial monitoring. In conclusion, the methods in this subcategory, "fixing the two ends of an FBG," are prominent because of the advantages of large tunability and frequency modulation.

\section{Conflict of Interests}

The author declares that there is no conflict of interests regarding the publication of this paper.

\section{References}

[1] K. O. Hill and G. Meltz, "Fiber Bragg grating technology fundamentals and overview," Journal of Lightwave Technology, vol. 15, no. 8, pp. 1263-1276, 1997.

[2] A. D. Kersey, M. A. Davis, H. J. Patrick et al., "Fiber grating sensors," Journal of Lightwave Technology, vol. 15, no. 8, pp. 1442-1463, 1997. 
[3] Y.-J. Rao, "In-fibre Bragg grating sensors," Measurement Science and Technology, vol. 8, no. 4, pp. 355-375, 1997.

[4] B. Lee, "Review of the present status of optical fiber sensors," Optical Fiber Technology, vol. 9, no. 2, pp. 57-79, 2003.

[5] M. Jones, "Structural-health monitoring: a sensitive issue," Nature Photonics, vol. 2, no. 3, pp. 153-154, 2008.

[6] D. Graham-Rowe, "Sensors take the strain," Nature Photonics, vol. 1, no. 6, pp. 307-309, 2007.

[7] T. H. T. Chan, L. Yu, H. Y. Tam et al., "Fiber Bragg grating sensors for structural health monitoring of Tsing Ma bridge: background and experimental observation," Engineering Structures, vol. 28, no. 5, pp. 648-659, 2006.

[8] P. Antunes, R. Travanca, H. Rodrigues et al., "Dynamic structural health monitoring of slender structures using optical sensors," Sensors, vol. 12, no. 5, pp. 6629-6644, 2012.

[9] V. Mishra, N. Singh, U. Tiwari, and P. Kapur, "Fiber grating sensors in medicine: current and emerging applications," Sensors and Actuators A: Physical, vol. 167, no. 2, pp. 279-290, 2011.

[10] L. Dziuda, F. W. Skibniewski, M. Krej, and J. Lewandowski, "Monitoring respiration and cardiac activity using fiber Bragg grating-based sensor," IEEE Transactions on Biomedical Engineering, vol. 59, no. 7, pp. 1934-1942, 2012.

[11] Y.-J. Rao, D. J. Webb, D. A. Jackson, L. Zhang, and I. Bennion, "In-fiber Bragg-grating temperature sensor system for medical applications," Journal of Lightwave Technology, vol. 15, no. 5, pp. 779-785, 1997.

[12] L. Mohanty, S. C. Tjin, D. T. T. Lie, S. E. C. Panganiban, and P. K. H. Chow, "Fiber grating sensor for pressure mapping during total knee arthroplasty," Sensors and Actuators A: Physical, vol. 135, no. 2, pp. 323-328, 2007.

[13] G. Rajan, D. Callaghan, Y. Semenova, M. McGrath, E. Coyle, and G. Farrell, "A fiber Bragg grating-based all-fiber sensing system for telerobotic cutting applications," IEEE Sensors Journal, vol. 10, no. 12, pp. 1913-1920, 2010.

[14] A. Laudati, F. Mennella, M. Giordano, G. D’Altrui, C. Calisti Tassini, and A. Cusano, "A fiber-optic Bragg grating seismic sensor," IEEE Photonics Technology Letters, vol. 19, no. 24, pp. 1991-1993, 2007.

[15] Y. Zhang, S. Li, Z. Yin, B. Chen, H.-L. Cui, and J. Ning, "FiberBragg-grating-based seismic geophone for oil/gas prospecting," Optical Engineering, vol. 45, no. 8, Article ID 084404, 2006.

[16] G. Gagliardi, M. Salza, P. Ferraro et al., "Design and test of a laser-based optical-fiber Bragg-grating accelerometer for seismic applications," Measurement Science \& Technology, vol. 19, no. 8, Article ID 085306, 2008.

[17] K. Li, Z. A. Zhou, A. C. Liu, X. P. Ye, H. X. Li, and D. Q. Cheng, "Using fiber Bragg grating in geothermal monitoring," in Rock Stress and Earthquakes, F. Xie, Ed., pp. 815-817, Taylor \& Francis Group, 2010.

[18] A. Gusarov, "Long-term exposure of fiber Bragg gratings in the BR1 low-flux nuclear reactor," IEEE Transactions on Nuclear Science, vol. 57, no. 4, pp. 2044-2048, 2010.

[19] K. S. Kim, Y. C. Song, G. S. Pang, and D. J. Yoon, "Study on the application of Fiber Bragg Grating sensors for the containment structures of nuclear power plants," in Smart Structures and Materials 2005: Sensors and Smart Structures Technologies for Civil, Mechanical, and Aerospace, Pts 1 and 2, M. Tomizuka, Ed., pp. 584-590, 2005.

[20] A. F. Fernandez, A. I. Gusarov, B. Brichard et al., "Temperature monitoring of nuclear reactor cores with multiplexed fiber Bragg grating sensors," Optical Engineering, vol. 41, no. 6, pp. 1246-1254, 2002.
[21] E. Udd, "25 Years of structural monitoring using fiber optic sensors," in Smart Sensor Phenomena, Technology, Networks, and Systems 2011, W. Ecke, K. J. Peters, and T. E. Matikas, Eds., vol. 7982 of Proceedings of SPIE, 2011.

[22] M. Buric, T. Chen, M. Maklad, P. R. Swinehart, and K. P. Chen, "Multiplexable low-temperature fiber Bragg grating hydrogen sensors," IEEE Photonics Technology Letters, vol. 21, no. 21, pp. 1594-1596, 2009.

[23] Smartfibres, "FBG applications," http://www.smartfibres.com/ FBG-sensors.

[24] FBGS, "FBG applications," http://www.fbgs.com/.

[25] Timbercon, "FBG applications," http://www.timbercon.com/ fiber-bragg-grating-sensor-technology/.

[26] National-Instruments, "FBG applications," http://www.ni.com/ opticalsensing/.

[27] FOS-TA, "FBG applications," http://www.fos-ta.com/.

[28] E. Udd, Fiber Optic Sensors: An Introduction for Engineers and Scientists, Wiley-Interscience, Hoboken, NJ, USA, 2006.

[29] J. Dakin and B. Culshaw, Optical Fiber Sensors, Artech House, 1988.

[30] R. Kashyap, Fiber Bragg Gratings, Academic Press, Cambridge, Mass, USA, 2009.

[31] J. L. Cruz, L. Dong, and L. Reekie, "Improved thermal sensitivity of fibre Bragg gratings using a polymer overlayer," Electronics Letters, vol. 32, no. 4, pp. 385-387, 1996.

[32] S. Gupta, T. Mizunami, T. Yamao, and T. Shimomura, "Fiber Bragg grating cryogenic temperature sensors," Applied Optics, vol. 35 , no. 25 , pp. 5202-5205, 1996.

[33] J. Jung, H. Nam, B. Lee, J. O. Byun, and N. S. Kim, "Fiber Bragg grating temperature sensor with controllable sensitivity," Applied Optics, vol. 38, no. 13, pp. 2752-2754, 1999.

[34] T. Mizunami, H. Tatehata, and H. Kawashima, "High-sensitivity cryogenic fibre-Bragg-grating temperature sensors using Teflon substrates," Measurement Science \& Technology, vol. 12, no. 7, pp. 914-917, 2001.

[35] S. W. James, R. P. Tatam, A. Twin, M. Morgan, and P. Noonan, "Strain response of fibre Bragg grating sensors at cryogenic temperatures," Measurement Science and Technology, vol. 13, no. 10, pp. 1535-1539, 2002.

[36] C. Lupi, F. Felli, L. Ippoliti et al., "Metal coating for enhancing the sensitivity of fibre Bragg grating sensors at cryogenic temperature," Smart Materials \& Structures, vol. 14, no. 6, pp. N71-N76, 2005.

[37] K. Li, Z. A. Zhou, and A. Liu, "A high sensitive fiber Bragg grating cryogenic temperature sensor," Chinese Optics Letters, vol. 7, no. 2, pp. 121-123, 2009.

[38] K. Li, Z. Zhou, A. Liu, and X. Wang, "High-sensitivity fiber bragg grating temperature sensor at high temperature," Guangxue Xuebao/Acta Optica Sinica, vol. 29, no. 1, pp. 249-251, 2009.

[39] W. W. Morey and W. L. Glomb, "Incorporated Bragg filter temperature compensated optical waveguide device," US Patent 07/456,440, 1991.

[40] G. W. Yoffe, P. A. Krug, F. Ouellette, and D. A. Thorncraft, "Passive temperature-compensating package for optical-fiber gratings," Applied Optics, vol. 34, no. 30, pp. 6859-6861, 1995.

[41] M. G. Xu, J.-L. Archambault, L. Reekie, and J. P. Dakin, "Discrimination between strain and temperature effects using dualwavelength fiber grating sensors," Electronics Letters, vol. 30, no. 13, pp. 1085-1087, 1994. 
[42] M. G. Xu, L. Dong, L. Reekie, J. A. Tucknott, and J. L. Cruz, "Temperature-independent strain sensor using a chirped Bragg grating in a tapered optical fibre," Electronics Letters, vol. 31, no. 10, pp. 823-825, 1995.

[43] S. W. James, M. L. Dockney, and R. P. Tatam, "Simultaneous independent temperature and strain measurement using infibre Bragg grating sensors," Electronics Letters, vol. 32, no. 12, pp. 1133-1134, 1996.

[44] M. H. Song, S. B. Lee, S. S. Choi, and B. H. Lee, "Simultaneous measurement of temperature and strain using two fiber Bragg gratings embedded in a glass tube," Optical Fiber Technology, vol. 3, no. 2, pp. 194-196, 1997.

[45] Y. L. Lo, "Using in-fiber Bragg-grating sensors for measuring axial strain and temperature simultaneously on surfaces of structures," Optical Engineering, vol. 37, no. 8, pp. 2272-2276, 1998.

[46] Y. Yu, H. Tam, W. Chung, and M. S. Demokan, "Fiber Bragg grating sensor for simultaneous measurement of displacement and temperature," Optics Letters, vol. 25, no. 16, pp. 1141-1143, 2000.

[47] X. Y. Dong, X. F. Yang, C.-L. Zhao, L. Ding, P. Shum, and N. Q. Ngo, "A novel temperature-insensitive fiber Bragg grating sensor for displacement measurement," Smart Materials \& Structures, vol. 14, no. 2, pp. N7-N10, 2005.

[48] K. Li and Z. Zhou, "A high sensitive fiber Bragg grating strain sensor with automatic temperature compensation," Chinese Optics Letters, vol. 7, no. 3, pp. 191-193, 2009.

[49] L. A. Fernandes, M. Becker, O. Frazão et al., "Temperature and strain sensing with femtosecond laser written Bragg gratings in defect and nondefect suspended-silica-core fibers," IEEE Photonics Technology Letters, vol. 24, no. 7, pp. 554-556, 2012.

[50] X. Y. Dong, C. L. Zhan, K. Hu, P. Shum, and C. C. Chan, “Temperature-insensitive tilt sensor with strain-chirped fiber Bragg gratings," IEEE Photonics Technology Letters, vol. 17, no. 11, pp. 2394-2396, 2005.

[51] H.-J. Chen, L. Wang, and W. F. Liu, "Temperature-insensitive fiber Bragg grating tilt sensor," Applied Optics, vol. 47, no. 4, pp. 556-560, 2008

[52] H. Y. Au, S. K. Khijwania, H. Y. Fu, W. H. Chung, and H. Y. Tam, "Temperature-insensitive fiber bragg grating based tilt sensor with large dynamic range," Journal of Lightwave Technology, vol. 29, no. 11, Article ID 5740549, pp. 1714-1720, 2011.

[53] B.-O. Guan, H.-Y. Tam, and S.-Y. Liu, "Temperature-independent fiber Bragg grating tilt sensor," IEEE Photonics Technology Letters, vol. 16, no. 1, pp. 224-226, 2004.

[54] R. Aneesh, M. Maharana, P. Munendhar, H. Y. Tam, and S. K. Khijwania, "Simple temperature insensitive fiber Bragg grating based tilt sensor with enhanced tunability," Applied Optics, vol. 50, no. 25, pp. E172-E176, 2011.

[55] S. He, X. Dong, K. Ni, Y. Jin, C. C. Chan, and P. Shum, “Temperature-insensitive $2 \mathrm{D}$ tilt sensor with three fiber Bragg gratings," Measurement Science and Technology, vol. 21, no. 2, Article ID 025203, 2010.

[56] K. Ni, X. Dong, Y. Jin, and H. Xu, “Temperature-independent fiber Bragg grating tilt sensor," Microwave and Optical Technology Letters, vol. 52, no. 10, pp. 2250-2252, 2010.

[57] K. Li, T. H. T. Chan, M. H. Yau, D. P. Thambiratnam, and H. Y. Tam, "Experimental verification of the modified spring-mass theory of fiber Bragg grating accelerometers using transverse forces," Applied Optics, vol. 53, no. 6, pp. 1200-1211, 2014.
[58] K. Li, T. H. T. Chan, M. H. Yau, D. P. Thambiratnam, and H. Y. Tam, "Biaxial fiber Bragg grating accelerometer using axial and transverse forces," IEEE Photonics Technology Letters, vol. 26, no. 15, pp. 1549-1552, 2014.

[59] K. Li, T. H. T. Chan, M. H. Yau, T. Nguyen, D. P. Thambiratnam, and H. Y. Tam, "Very sensitive fiber Bragg grating accelerometer using transverse forces with an easy over-range protection and low cross axial sensitivity," Applied Optics, vol. 52, no. 25, pp. 6401-6410, 2013.

[60] A. Stefani, S. Andresen, W. Yuan, N. Herholdt-Rasmussen, and O. Bang, "High sensitivity polymer optical fiber-Bragg-gratingbased accelerometer," IEEE Photonics Technology Letters, vol. 24, no. 9, pp. 763-765, 2012.

[61] S. R. K. Morikawa, A. S. Ribeiro, R. D. Regazzi, L. C. G. Valente, and A. M. B. Braga, "Triaxial Bragg grating accelerometer," in Proceedings of the 15th Optical Fiber Sensors Conference Technical Digest, vol. 1, pp. 95-98, IEEE, Portland, Ore, USA, May 2002.

[62] P. Antunes, H. Varum, and P. S. André, "Uniaxial fiber Bragg grating accelerometer system with temperature and cross axis insensitivity," Measurement, vol. 44, no. 1, pp. 55-59, 2011.

[63] P. F. Costa Antunes, C. A. Marques, H. Varum, and P. S. Andre, "Biaxial optical accelerometer and high-angle inclinometer with temperature and cross-axis insensitivity," IEEE Sensors Journal, vol. 12, no. 7, pp. 2399-2406, 2012.

[64] J. Zhang, X. Qiao, M. Hu et al., "Proposal of metal bellows-based fiber Bragg grating accelerometer," Chinese Optics Letters, vol. 9, no. 9, Article ID 090606, 2011.

[65] T. A. Berkoff and A. D. Kersey, "Experimental demonstration of a fiber bragg grating accelerometer," IEEE Photonics Technology Letters, vol. 8, no. 12, pp. 1677-1679, 1996.

[66] Y. X. Guo, D. S. Zhang, H. Meng, X. Y. Wen, and Z. D. Zhou, "Metal packaged fiber Bragg grating accelerometer," in 22nd International Conference on Optical Fiber Sensors (OFS '12), vol. 8421 of Proceedings of SPIE, Beijing, China, October 2012.

[67] K. Li, M. H. Yau, T. H. T. Chan, D. Thambiratnam, and H. Y. Tam, "Fiber Bragg grating strain modulation based on nonlinear string transverse-force amplifier," Optics Letters, vol. 38, no. 3, pp. 311-313, 2013.

[68] K. Li, T. H. Chan, M. H. Yau, D. P. Thambiratnam, and H. Y. Tam, "Fiber Bragg grating accelerometer based on a transversely rotating stick," Optik, vol. 126, no. 23, pp. 4337-4341, 2015.

[69] H.-J. Sheng, W.-F. Liu, K.-R. Lin, S.-S. Bor, and M.-Y. Fu, "Highsensitivity temperature-independent differential pressure sensor using fiber Bragg gratings," Optics Express, vol. 16, no. 20, pp. 16013-16018, 2008.

[70] Y. S. Hsu, L. Wang, W.-F. Liu, and Y. J. Chiang, “Temperature compensation of optical fiber Bragg grating pressure sensor," IEEE Photonics Technology Letters, vol. 18, no. 7, pp. 874-876, 2006.

[71] H.-J. Sheng, M.-Y. Fu, T.-C. Chen, W.-F. Liu, and S.-S. Bor, "A lateral pressure sensor using a fiber Bragg grating," IEEE Photonics Technology Letters, vol. 16, no. 4, pp. 1146-1148, 2004.

[72] Y.-Q. Liu, Z.-Y. Guo, Z.-G. Liu, D.-H. Zhao, C.-F. Ge, and X.-Y. Dong, "Fiber grating sensor with enhanced pressure and temperature sensitivity," Chinese Physics Letters, vol. 17, no. 2, pp. 115-116, 2000.

[73] M. G. Xu, H. Geiger, and J. P. Dakin, "Fibre grating pressure sensor with enhanced sensitivity using a glass-bubble housing," Electronics Letters, vol. 32, no. 2, pp. 128-129, 1996. 
[74] Y. Zhang, D. Feng, Z. Liu et al., "High-sensitivity pressure sensor using a shielded polymer-coated fiber Bragg grating," IEEE Photonics Technology Letters, vol. 13, no. 6, pp. 618-619, 2001.

[75] T. Guo, Q. Zhao, H. Zhang et al., “Temperature-insensitive fiber Bragg grating dynamic pressure sensing system," Optics Letters, vol. 31, no. 15, pp. 2269-2271, 2006.

[76] L. Mohanty, L. M. Koh, and S. C. Tjin, "Fiber Bragg grating microphone system," Applied Physics Letters, vol. 89, no. 16, Article ID 161109, 2006.

[77] G. B. Hocker, "Fiber-optic sensing of pressure and temperature," Applied Optics, vol. 18, no. 9, pp. 1445-1448, 1979.

[78] M. G. Xu, L. Reekie, Y. T. Chow, and J. P. Dakin, "Optical in-fibre grating high pressure sensor," Electronics Letters, vol. 29, no. 4, pp. 398-399, 1993.

[79] Y. Dai, M. Yang, G. Xu, and Y. Yuan, "Magnetic field sensor based on fiber Bragg grating with a spiral microgroove ablated by femtosecond laser," Optics Express, vol. 21, no. 14, pp. 1738617391, 2013.

[80] J. Mora, A. Díez, J. L. Cruz, and M. V. Andrés, "A magnetostrictive sensor interrogated by fiber gratings for DC-current and temperature discrimination," IEEE Photonics Technology Letters, vol. 12, no. 12, pp. 1680-1682, 2000.

[81] K. S. Chiang, R. Kancheti, and V. Rastogi, “Temperature-compensated fiber-Bragg-grating-based magnetostrictive sensor for dc and ac currents," Optical Engineering, vol. 42, no. 7, pp. 19061909, 2003.

[82] C. Ambrosino, S. Campopiano, A. Cutolo, and A. Cusano, "Sensitivity tuning in terfenol-D based fiber Bragg grating magnetic sensors," IEEE Sensors Journal, vol. 8, no. 9, pp. 1519-1520, 2008.

[83] M. H. Yang, J. X. Dai, C. M. Zhou, and D. S. Jiang, “Optical fiber magnetic field sensors with TbDyFe magnetostrictive thin films as sensing materials," Optics Express, vol. 17, no. 23, pp. 2077720782, 2009.

[84] J. X. Dai, M. H. Yang, X. B. Li, H. L. Liu, and X. L. Tong, "Magnetic field sensor based on magnetic fluid clad etched fiber Bragg grating," Optical Fiber Technology, vol. 17, no. 3, pp. 210213, 2011.

[85] G. N. Smith, T. Allsop, K. Kalli et al., "Characterisation and performance of a Terfenol-D coated femtosecond laser inscribed optical fibre Bragg sensor with a laser ablated microslot for the detection of static magnetic fields," Optics Express, vol. 19, no. 1, pp. 363-370, 2011.

[86] H. Liu, S. W. Or, and H. Y. Tam, "Magnetostrictive compositefiber Bragg grating (MC-FBG) magnetic field sensor," Sensors and Actuators A: Physical, vol. 173, no. 1, pp. 122-126, 2012.

[87] X.-Z. Lin, Y. Zhang, H.-L. An, and H.-D. Liu, "Electrically tunable singlemode fibre Bragg reflective filter," Electronics Letters, vol. 30, no. 11, pp. 887-888, 1994.

[88] P. M. Cavaleiro, F. M. Araújo, and A. B. L. Ribeiro, "Metalcoated fibre Bragg grating sensor for electric current metering," Electronics Letters, vol. 34, no. 11, pp. 1133-1135, 1998.

[89] H.-J. Sheng, P.-T. Tsai, W.-Y. Lee et al., "Random rotary position sensor based on fiber Bragg gratings," IEEE Sensors Journal, vol. 12, no. 5, pp. 1436-1441, 2012. 


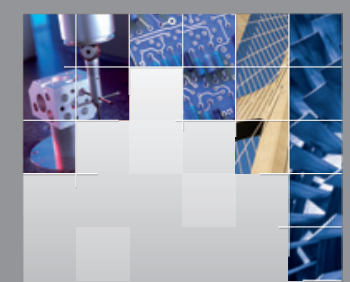

\section{Enfincering}
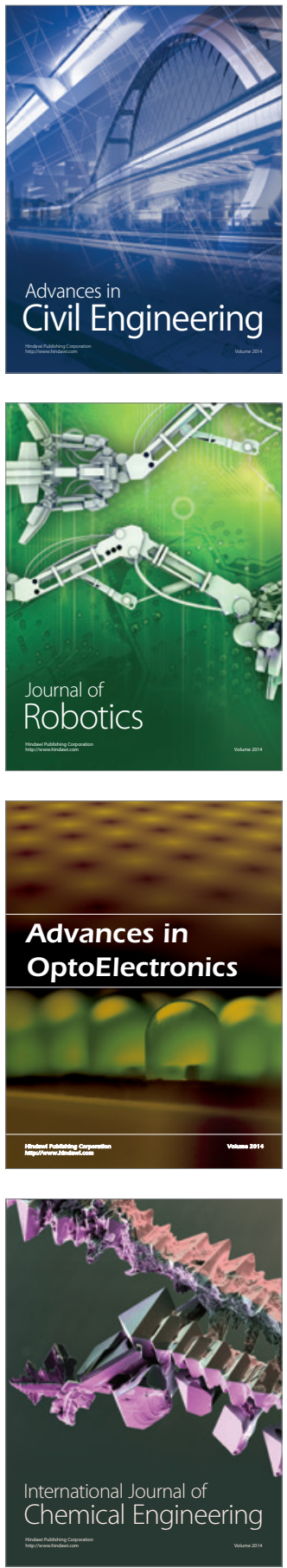

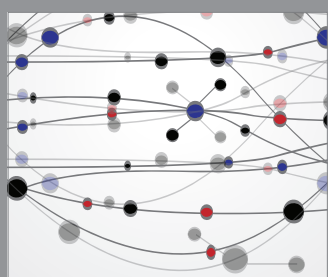

The Scientific World Journal

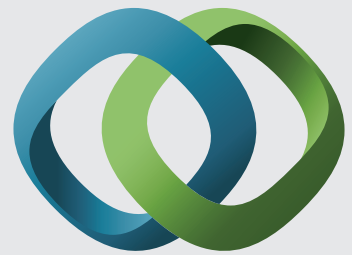

\section{Hindawi}

Submit your manuscripts at

http://www.hindawi.com
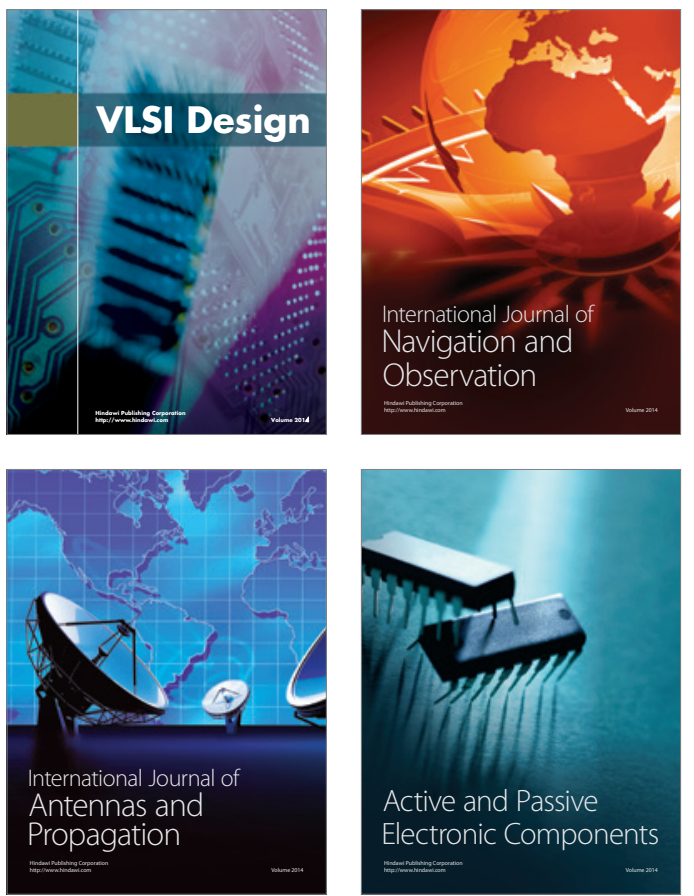
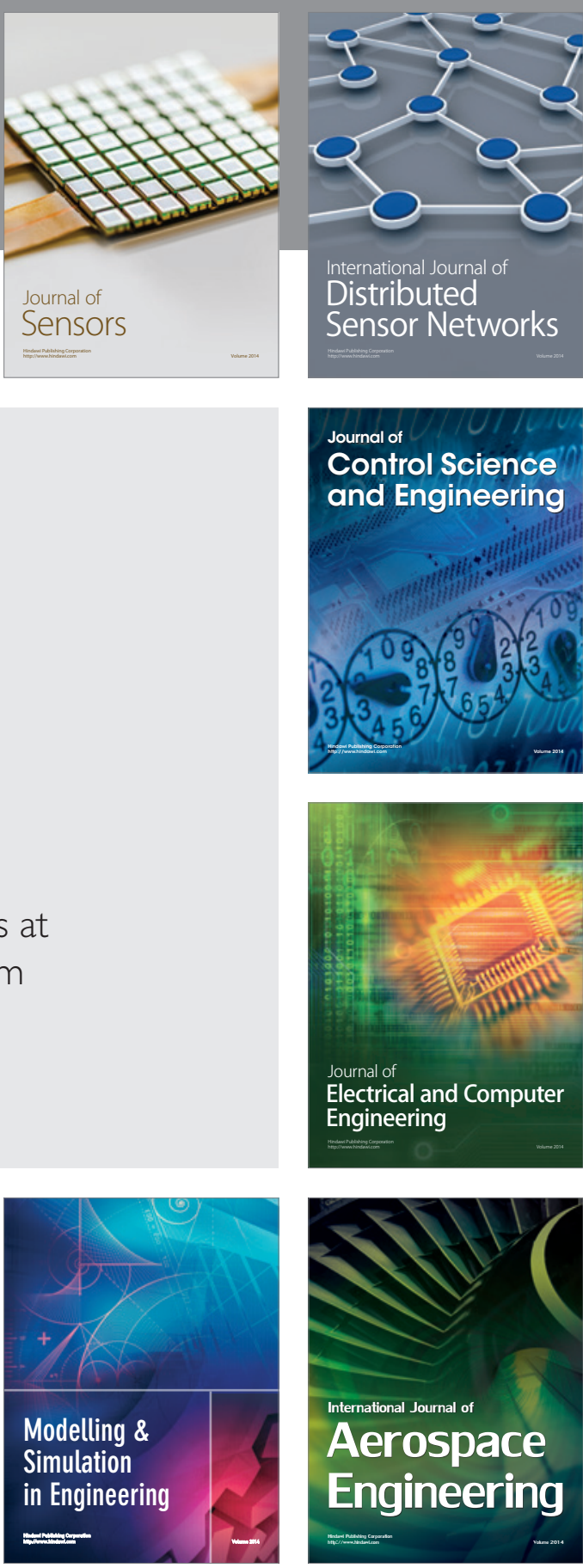

International Journal of

Distributed

Sensor Networks

Journal of

Control Science

and Engineering
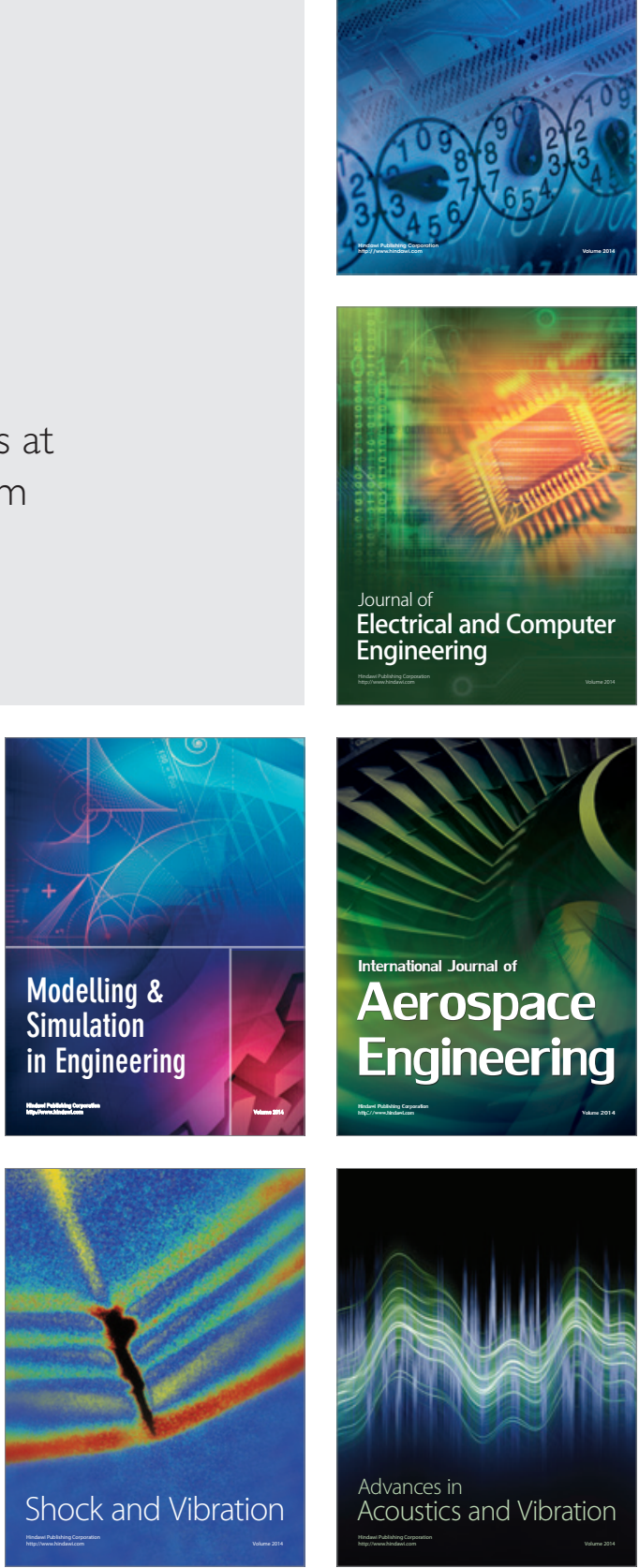